\title{
Um Retrato da Neuropsicologia no Brasil
}

Este número de PSICOLOGIA EM PESQUISA apresenta um retrato da Neuropsicologia brasileira atual. Não se trata de uma descrição exaustiva, mas dentre 32 trabalhos apresentados, os 12 selecionados mostram rumos relevantes das investigaçóes de nossa Neuropsicologia.

Recentemente, a Neuropsicologia ficou fortalecida, em parte, devido à valorização do estudo do cérebro e de tecnologias de imagens cerebrais. Entretanto, seu espectro de estudo e de atuação foi ampliado com a participaçáo interdisciplinar de profissionais da área da Saúde, das Ciências Humanas e da Educação, gerando propostas inovadoras de pesquisa e de trabalho clínico. O diálogo entre profissionais de áreas diversas criou um corpo de conhecimentos transdisciplinares, com características próprias. Este diálogo está na origem deste número temático, planejado por um psicólogo, uma fonoaudióloga e um neurologista, semelhante à publicação considerada marco inicial da interdisciplinaridade no Ocidente (Alajouanine, Ombredane \& Durant, 1939). Entretanto, ao invés de focalizar um tipo específico de distúrbio neuropsicológico, esta publicação evidencia a larga abrangência atual da Neuropsicologia, com uma diversidade tanto teórica quanto metodológica.

O leitor interessado em Neuropsicologia Pediátrica encontrará aqui seis trabalhos. Fugindo de estudos tradicionais dirigidos ao funcionamento de um "cérebro ideal", a Neuropsicologia Pediátrica tem um grande desafio: verificar, além de influências ambientais, efeitos da mudança característica do desenvolvimento.

Um intrigante questionamento da posição do Conselho Federal de Psicologia é apresentado em "Os Equívocos e Acertos da Campanha 'Não à Medicalização da Vida". Constitui uma análise cuidadosa da concepção do Conselho e uma crítica através do levantamento aprofundado de vários conceitos neuropsicológicos relacionados ao Transtorno do Déficit de Atenção e Hiperatividade (TDAH).

A interessante revisão teórica "Avaliação das Funçôes Executivas na Infância” nos mostra como é complexo elaborar testes neuropsicológicos apoiados em conceitos teóricos e, ao mesmo tempo, válidos para outras populações fora do foco de "adultos ideais".

Uma questão original norteia "Avaliação da Linguagem e do Processamento Auditivo na Caracterização Neuropsicológica do TDAH": quantos estudos têm avaliado linguagem em crianças com TDAH relacionando-os coma alta incidência de comorbidades de disfunçôes de memória auditiva e de compreensão de leitura?

$\mathrm{O}$ artigo "Comparação entre Maus Compreendedores e Bons Leitores em Tarefas Neuropsicológicas" é essencial para profissionais preocupados com alfabetização. Com uma amostra de crianças entre a quarta e a sexta série, aponta os aspectos neuropsicológicos relacionados a dificuldades de compreensão textual.

Já "Does the Acute Cerebellitis Plays a Role in the Neurocognitive Profile of a Child After its Onset?" faz um minucioso estudo de caso retratando o trabalho clínico, mostrando a importante interação entre achados neuropsicológicos, dinâmica familiar, avaliaçáo de inteligência, desempenho escolar e estado emocional.

Ao final dos artigos relacionados à Neuropsicologia Pediátrica, encontramos um estudo com adolescentes, populaçáo normalmente esquecida pela Neuropsicologia, realizando um diálogo entre a Neuropsicologia e a Neuropsiquiatria em "Desempenho Neuropsicológico de Adolescentes com Transtorno de Humor Bipolar". O encontro dessas duas áreas é considerado recente. Vale a pena observar que no grupo pioneiro da interdisciplinaridade, o neurologista Alajouanine iniciou seus estudos em neuropsiquiatria. Talvez sua múltipla formação tenha favorecido aproximar diferentes áreas interessadas nas relaçôes entre cérebro e cognição.

Passando aos estudos com adultos, temos duas investigaçóes sobre transtornos vasculares cerebrais. No primeiro, podemos observar os passos iniciais para a normatizaçáo de uma bateria baseada em critérios psicolinguísticos em "Tarefas para Avaliação Psicolingüística no Português do Brasil”. De outro lado, o estudo de casos múltiplos "Avaliação da Memória de Pacientes com Lesão em Núcleos da Base e Tálamo Pós-AVC" analisa circuitos neurais e funcionais do núcleo da base e seu envolvimento em funções cognitivas, indo além de funçóes motoras do núcleo da base, descritas tradicionalmente.

Em relação às demências, o artigo "Screening for Executive Dysfunction with the Frontal Assessment Battery" fornece um material normatizado e capaz de avaliar funções executivas em pacientes com doença de Alzheimer. É um interessante artigo que situa no contexto brasileiro o material utilizado e a necessidade 
de examinar estas funções em pacientes portadores de Doença de Alzheimer. Já o artigo "Discourse Coherence and its Relation with Cognition in Alzheimer's Disease" baseia-se em modelos de coerência e mostra dificuldades de coerência local destes pacientes, que estáo relacionadas a diversas disfunçôes cognitivas. Além disso, em "Dissociação Entre Seres Vivos e Artefatos”, encontramos a adaptação brasileira de alguns testes da Bateria de Cambridge, que objetivam detectar dissociaçôes semânticas. São apresentados seus efeitos em adultos saudáveis e em dois pacientes.

O último artigo, "Uso de Medidas Quantitativas de Eficácia em Reabilitação Neuropsicológica”, incita pesquisadores a buscar um maior rigor científico, indicando medidas estatísticas para observar mudanças de intervenção.

Ao final, este número temático mostra o reconhecimento da Neuropsicologia brasileira por países vizinhos, com a entrevista do presidente da Sociedade Latino Americana de Neuropsicologia (SLAN), Prof. Luis Quintanar. Esta sociedade promove trabalhos desenvolvidos em países de língua latina. A troca de experiências e a colaboração internacionais, propiciada pela SLAN, com certeza favorecerá ainda mais o crescimento de nossas pesquisas.

O número temático se encerra com uma resenha do livro "Reabilitação Cognitiva: uma abordagem neuropsicológica integrada", escrito por M. Sohlberg e C. Mateer.

Maria Alice Pimenta

\section{Referências}

1. Alajouanine T., Ombredane A., \& Durand M. (1939). Le syndrome de désintégration phonétique dans l'aphasie. Paris: Masson. 